Virginia Commonwealth University

VCU Scholars Compass

1984

\title{
Cellular DNA Content as a Predictor of Response to Chemotherapy in Infants with Unresectable Neuroblastoma
}

\author{
A. Thomas Look \\ St. Jude Children's Research Hospital \\ F. Ann Hayes \\ St. Jude Children's Hospital \\ Ruprecht Nitschke \\ Oklahoma Children's Memorial Hospital
}

Nancy B. McWilliams

Medical College of Virginia

Alexander A. Green

Medical College of Virginia

Follow this and additional works at: http://scholarscompass.vcu.edu/vcuhealth_pubs

Part of the Medicine and Health Sciences Commons

From The New England Journal of Medicine, Look, A. T., Hayes, F. A., Nitschke, R. et al., Cellular DNA Content as a Predictor of Response to Chemotherapy in Infants with Unresectable Neuroblastoma, Vol. 311, Page 231, Copyright (C) 1984 Massachusetts Medical Society. Reprinted with permission.

\section{Downloaded from}

http://scholarscompass.vcu.edu/vcuhealth_pubs/12

This Article is brought to you for free and open access by the VCU Health at VCU Scholars Compass. It has been accepted for inclusion in VCU Health Publications by an authorized administrator of VCU Scholars Compass. For more information, please contact libcompass@vcu.edu. 


\title{
CELlULAR DNA CONTENT AS A PREDICTOR OF RESPONSE TO CHEMOTHERAPY IN INFANTS WITH UNRESECTABLE NEUROBLASTOMA
}

\author{
A. Thomas Look, M.D., F. Ann Hayes, M.D., Rupreght Nitschke, M.D., Nancy B. McWiliams, M.D., \\ and Ailexanider A. Green, M.D.
}

\begin{abstract}
We studied the relation between the DNA content of neuroblastoma cells and the response to therapy in 35 infants under one year of age with a diagnosis of neuroblastoma. Using flow cytometric techniques, we found that in 27 cases the primary malignant stem line consisted of neuroblasts with hyperdiploid DNA content, ranging from 1.07 to 2.42 times the finding in normal diploid cells. All remaining cases had diploid stem lines. Diploidy was more common in infants with clinical Stage D neuroblastoma (metastases beyond regional lymph nodes) than in those with other, less advanced stages: 6 of 10 as compared with 2 of $25(P=0.003)$. Of 17 evaluable pa-
\end{abstract}

$\mathrm{T}$ REATMEN'T protocols for children with malignant solid tumors are based largely on the histopathologic diagnosis, stage (extent) of disease, and certain other presenting features, such as age and sex. It is becoming increasingly clear, however, that many aspects of tumor-cell heterogeneity cannot be appreciated from clinical and patholngical descriptions alone.' $A$ bnormal cellular DNA content, an unequivo(al marker of malignant disease, has been linked to the rate of cell proliferation, stage of cell differcntiation, and prognosis in a variety of tumor types. ${ }^{2-4}$ The ability to detect this abnormality both rapidly and precisely with flow cytometric techniques has opened the way for improvement of tumor-staging systems and, hence, for more judicious selection of therapy.

We employed flow cytometry to investigate neuroblastoma in infants because of persistent questions regarding the course of disease in this age group. Unlike older patients, infants with unresectable neuroblastoma have a generally favorable prognosis. ${ }^{5-7}$ They are more likely to have a complete response to chemotherapy, and a large proportion of those with a complete response are apparently cured of their disease. Yet, for reasons that have been unclear, approximately one fourth of such patients have early resistance to antincoplastic drugs. It has not been possible, with conventional staging methods, to identify infants with a poor prognosis who might benefit from alternative chemotherapy.

Evans' Stage IV-S neuroblastoma - a unique tumor of infants - is characterized by small primary lesions and metastases to liver, skin, and bone marrow but not to bonc. Spontaneous regression has been observed with appreciable frequency in patients with

From the Division of Hematology-Oncology, St. Jude Children's Research Hospital, Memphis, Tenn.; Oklahoma Children's Memorial Hospital, Oklahoma City, Okla.: and the Medical College of Virginia, Richmond, Va. Address reprint requests to Dr. Look at the Pediatric Oncology Group, St. Louis Children's Hospital, 500 South Kingshighway Blvd., St. Louis, MO 63110.

Supported in part by a Cancer Center Support (Core) grant (CA21765); a Solid Tumor Program Project grant (CA23099): Pediatric Oncology Group Participation grants (CA31566, CA41233, CA28530, CA29139. and CA30969); and the American Lebancse Syrian Associated Charitics (ALSAC). tients with unresectable hyperdiploid tumors, 15 had complete responses and two had partial responses to cyclophosphamide and doxorubicin; six others with diploid tumors did not respond $(P=0.00001)$. We also found that each of the four infants with Evans' Stage IV-S neuroblastoma, an unusual form of disseminated neuroblastoma with a relatively good prognosis, had hyperdiploid tumor cells of clonal origin.

We conclude that in neuroblastoma of infants, hyperdiploidy of tumor cells is associated with a better response to chemotherapy than is diploidy. ( $N$ Engl J Med 1984; 311:231-5.)

this special category of disseminated tumor. ${ }^{7-11}$ 'To account for spontaneous regression of Stage IV-S disease on a genetic basis, Knudson and Meadows ${ }^{11}$ proposed that such tumors do not involve malignant cells at all, but rather hyperplastic nodules of mutant cells that lack an additional mutation needed for malignant growth. 'This possibility, in the light of the effectiveness of chemotherapy for most infants with ncuroblastoma, poses a therapeutic dilemma: Should treatment be withheld in infants with Stage IV-S disease, or should it be administered as aggressively as for other forms of disseminated tumor?

Our findings indicate that hyperdiploid DNA content of the malignant cells is a favorable prognostic feature in infants with unresectable neuroblastoma treated with cyclophosphamide and doxorubicin. All infants with Stage IV-S disease had clonal hyperdiploid abnormalities, which were indicative of malignant discase and not of benign hyperplasia.

\section{Methods}

\section{Patients}

Tumor cells from 35 infants under one year of age with a diagnosis of neuroblastona were studied by flow cytometry at St. Jude Children's Research Hospital. The patients were admitted either to St. Jude Hospital (10 patients) or to other institutions in the Pediatric Oncology Group (25 patients) from March 30, 1978, through August 31, 1983.

\section{Staging and Treatment}

Tumor staging at diagnosis was based on the criteria of the Pediatric Oncology Group. Stage A denotes complete excision of gross primary tumor in the absence of inctastases, and Stage B incomplete excision; Stage C denotes tumor dissemination to regional nodes, Stage D tumor dissemination beyond regional nodes and Stage I)(IV-S) tumor dissemination limited to liver, skin, or bone marrow. None of the patients with Stage $A$ disease received chemotherapy because, with few exceptions, surgery alone has been curative in such cases, even when microscopic residual disease has been present. ${ }^{6.7 .12}$

The 24 infants with unresectable tumor (Stages B, C, D, and I)(IV-S)) were treated uniformly with $150 \mathrm{mg}$ of cyclophosphamide per square meter of body-surface area by mouth or intravenously on Days 1 through 7 and $35 \mathrm{mg}$ of doxorubicin per square meter intravenously on Day 8 . Responses were evaluated after five courses of 
the drug combination." Only one patient - an infant in whom hepatic toxicity developed after two courses of therapy - could not be assessed.

\section{Flow Cytometry}

Tumor samples obtained at surgery or bone--marrow aspirates obtained before antineoplastic therapy were used to determine the DNA content of neuroblasts. Ciell suspensions were made by mincing the tumor specimens with a scalpel in RPMI-1640 culture medium. The percentage of tumor cells in the samples used for flow cytometric analysis was determined from differential counts done on Wright-stained smears of tumor-cell suspensions or bone-marrow aspirates. Only samples with more than 10 per cent neuroblasts as determined by differential count were analyzed for cellular DNA content. Aliquots of suspended cells, each containing $2 \times 10^{6}$ cells, were centrifuged at $1500 \mathrm{rpm}$ for five minutes at room temperature; the medium was discarded, and the pellets were stained with $1 \mathrm{ml}$ of a hypotonic solution of propidium iodide citrate. ${ }^{13}$

Fluorescence exceeding $590 \mathrm{~nm}$, emitted from the propidium iodide-DNA complex in each cell nucleus, was measured with a Coulter TPS-1 or EPICS V flow cytometer (Coulter Electronics, Hialeah, Fla.) as previously described. ${ }^{14}$ DN $\Lambda$ histograms were analyzed for the DN $\Lambda$ index of the neuroblastoma stem line or lines. This index is the ratio of the modal $G_{0} / G_{1}$ channel number for neuroblastoma cells to that of normal diploid cells (hence, the DN $\Lambda$ index of diploid neuroblasts $=1,0$ ). The coefficient of variation for $\mathrm{G}_{0} / \mathrm{G}_{1}$-phase neuroblasts, the percentage of $S$-phase cells, and the presence of diploid or multiple stem lines were determined as previously described. ${ }^{14}$

To make allowance for possible variation in the DNA index and the percentage of $\mathrm{S}$-phase cells in samples from large tumor masses, we analyzed two to five separate specimens in 19 cases and used the median values in subsequent comparisons. Individual values differed from median DNA indexes by 0.00 to 0.06 units (median difference, 0.01 units) and from median percentages of S-phase cells by 0.0 to 4.8 per cent (median difference, 1.9 per cent).

\section{Statistical Analysis}

Descriptive statistics, correlations, nonparametric comparisons of the median percentages of S-phase cells, and least-squares lincar regressions were carried out with the Minitab computing system. ${ }^{15}$ Proportions of patients with and without responses to chemotherapy were compared by means of the gencralization of Fisher's exact test. ${ }^{16}$ Comparisons of median percentage: S-phase values among patients grouped according to stage of disease were made with the Kruskal-Wallis test. ${ }^{17}$ All tests of significance were two-sided.

\section{Results}

Flow cytometric analysis of malignant neuroblasts disclosed the presence of threc distinct categories of cellular DNA content (Fig. 1). Seven of the 35 patients (20 per cent) had a single diploid malignant stem line (Fig. 1, Panel A). Twenty-two (63 per cent) had single hyperdiploid stem lines (Panel B), and six (17 per cent) had multiple lines (Panel C). All cases in the latter category were classified according to the stem line of lowest ploidy; thus, five were considered hyperdiploid, and one diploid. The very low coefficients of variation for populations of malignant $G_{0} / G_{1}$ cells (mean \pm S.D., $3.3 \pm 0.8$ ) indicated that each stem line arose from a single cell with abnormal DNA content. Residual diploid $G_{0} / G_{1}$ cells, present in all hyperdiploid cases, could be accounted for by the presence of recognizable normal marrow or peripheral-blood cells in the suspension.
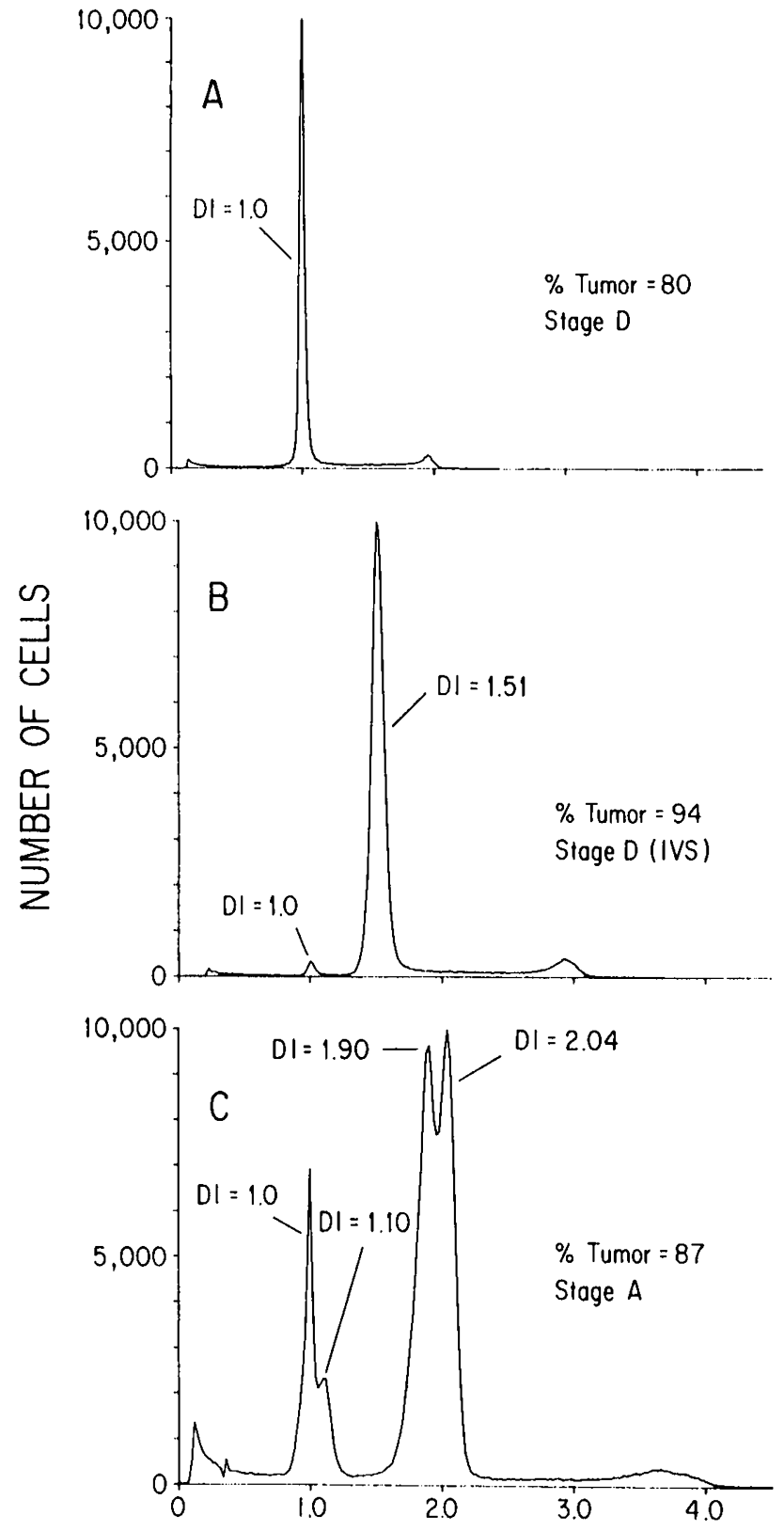

RELATIVE DNA CONTENT

Figure 1. Representative DNA Histograms Demonstrating Three Discrete Categories of Stem-Line Ploidy.

In Panel A, the DNA content of the tumor cells cannot be distinguished from that of residual normal marrow cells (DNA index $[D I]=1.0)$. Panel $B$ shows results from neuroblasts obtained at tumor biopsy from an infant with Evans' Stage IV-S disease and hyperdiploid DNA content (DNA index $=1.51$ ). A small peak of diploid $G_{0} / G_{1}$ blood cells is evident, accounting for 2 per cent of the cells analyzed in the histogram and corresponding to the 6 per cent fraction of nontumor cells determined from a differential count on Wright-stained smears. The neuroblasts in Panel $\mathrm{C}$, also obtained by tumor biopsy, are those of an infant with localized disease and multiple neuroblastoma stem lines. Peaks of $G_{0} / G_{1}$ cells with DNA indexes of 1.10, 1.90, and 2.04 are evident. By differential count, nontumor (peripheral-blood) cells made up 13 per cent of the sample and hence accounted for the peak of diploid $G_{0} / G_{1}$ cells. 


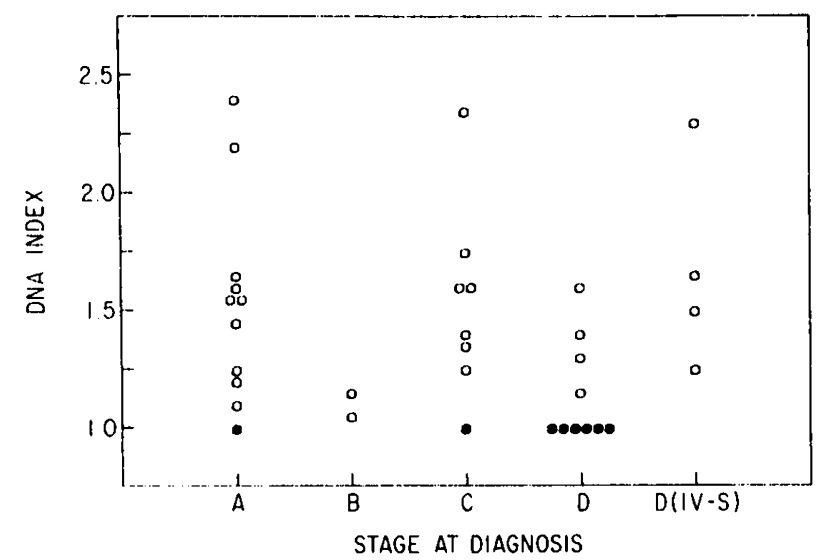

Figure 2. Distribution of the DNA Indexes of Primary Malignant Stem Lines in 35 Patients, According to the Stage of the Disease at Diagnosis.

Closed circles indicate stem lines with diploid DNA indexes (1.0), and open circles those with hyperdiploid DNA indexes. The staging system is explained in the text.

Figure 2 shows the distribution of flow cytometric findings according to tumor stage at diagnosis. In the 27 hyperdiploid cases, DNA indexes ranged from 1.07 to 2.42 times the diploid value. Diploidy was significantly more frequent among patients with Stage D neuroblastoma than among those with other presenting stages ( 6 of 10 patients vs. 2 of $25, P=0.003$ ). Most striking was the presence of clonal hyperdiploid abnormalities in all four cases of Stage D(IV-S) neuroblastoma (Fig. 1B). When the DNA index was determined in both bone marrow and primary tumor, ploidy findings did not vary with tissue type, indicating that the DNA content of malignant neuroblasts is a clonal property that is independent of disease site.

Cell proliferative activity, as reflected by the percentage of S-phase cells, has been linked to DNA index and disease stage in a variety of malignant solid tumors in adults. ${ }^{2,3}$ We therefore determined this fraction for the 25 patients whose samples had more than 70 per cent neuroblasts. The results varied widely, from 4.7 to 39.4 per cent (median, 13.4), with no significant variation among median values for different discase stages $(P=0.34)$. The median percentage of S-phase cells for the three assessable patients with unresectable diploid tumors was significantly higher than the value for the 14 with unresectable hyperdiploid disease (26.9 vs. 12.6 per cent, $\mathrm{P}=0.01$ ). Among hyperdiploid cases, the percentage of S-phase cells did not correlate with DNA index $(r=-0.16$, $\mathrm{P}=0.5)$.

Twenty-three patients, representing four stages of unresectable neuroblastoma, could be assessed for responsiveness to cyclophosphamide and doxorubicin. Of the 17 patients with hyperdiploid stem lines, 15 had complete responses and 2 had partial responses; the six whose tumor cells were diploid did not respond $(P=0.00001)$. The only other variable with a signifi- cant bearing on treatment response was the tumor stage at diagnosis $(P=0.018)$. The independent prognostic value of the DNA index was indicated by the ability of the marker to distinguish the five patients with Stage D disease who did not respond $(P=0.008)$. The percentage of $S$-phase cells was uniformly high in the threc nonresponding patients with analyzable results $(19.4,26.9$, and 39.4 per cent).

All 17 patients who responded, including the four with Stage D (IV-S) disease, had been clinically free of disease at this writing for a median of 18 months after diagnosis (range, 5 to 55 months). The two patients who responded partially had complete resection of residual tumor after their planned chemotherapy. Of the six with diploid stem lines who did not respond, four subsequently had complete responses to cisplatin and teniposide. ${ }^{18}$ Similarly, two other infants with Stage D tumor who did not have flow cytometric studies at diagnosis did not respond to cyclophosphamide and doxorubicin but had complete responses to cisplatin and teniposide. Analysis of their tumor cells, obtained surgically after induction therapy, disclosed DNA indexes of 1.0 in each case.

\section{Discussion}

The most reliable prognostic factors in neuroblastoma have been the age of the child and the stage of disease at diagnosis. ${ }^{5-7.12,19}$ We report here the surprising result that hyperdiploid DNA content of the malignant cells predicts the response to cyclophosphamide and doxorubicin in infants with unresectable tumor. Other biologic markers with apparent prognostic valuc have becn identified in neuroblastoma. Hann et al. ${ }^{20}$ found higher serum ferritin levels and greater inhibition of E-rosette formation in patients with Evans' Stage IV neuroblastoma than in those with Stage IV-S disease. Pinkel ${ }^{21}$ has pointed out, however, that the patients with Stage IV disease who were studied were older (median, two years) than the patients with Stage IV-S disease (median, four months), so that age-specific differences cannot be excluded as the cause of variation in these markers. Elevated serum levels of neuron-specific enolase have been reported by Zeltzer et al. ${ }^{22}$ to predict a poor outcome for infants with Stage IV ncuroblastoma.

Detection of an abnormal DNA index depends primarily on the gain or loss of whole chromosomes of average size, as indicated by studies of leukemic cells ${ }^{3,14,23}$ in which flow cytometric measurements were directly correlated with malignant stem-line ploidy determined from karyotypes. It should be stressed that neuroblastoma cells with diploid DNA content as determined by flow cytometry may contain double-minute chromatin bodies or chromosomes with structural abnormalities and homogeneously staining regions not detectable by this technique. ${ }^{24}$ Correlations of chromosome karyotype with flow cytometric data have been hampered in neuroblastoma by the difficulty of obtaining interpretable karyotypes 
from primary tumor material. This underscores the clinical importance of flow cytometry as a rapid and accurate means of estimating the ploidy of malignant stem lines.

The observed association between hyperdiploid stem lines and a favorable response to chemotherapy has a striking precedent in acutc lymphoblastic leukcmia of childhood. Several groups have reported an independent effect of chromosome number on the duration of disease-free survival..$^{25-27}$ In the largest series of patients, Williams et al. ${ }^{25}$ found that remissions were significantly longer for children with a chromosome number greater than 50. By contrast, the prognosis for adults with malignant solid tumors has generally been worse when DN $A$ indexes have been high, ${ }^{3}$ perhaps reflecting different mechanisms of carcinogenesis in this age group as compared with children bearing tumors of developmental origin.

It may be important that the median percentage of S-phase cells for patients with diploid neuroblastoma that is unresponsive to cyclophosphamide and doxorubicin was twice the value for patients with hyperdiploid disease that was responsive. Barlogic et al." have shown that in certain malignant solid tumors in adults, the percentage of S-phase cells increases with the degree of hyperdiploidy and that cases with the highest S-phase values involve advanced stages of disease and a poor prognosis. Thus, the link between our unresponsive diploid cases and the hyperdiploid cases reported by Barlogie could reside in the cell proliferative rate, even though the correlation between the percentage of S-phase cells and ploidy was reversed.

Evans et al. ${ }^{7}$ were the first to call attention to an unusual form of disseminated ncuroblastoma, Stage IV-S, which is characterized by a lack of bone involvement and a good prognosis. The relatively high frequency of spontaneous regression reported for Stage IV-S neuroblastoma led Knudsen and Meadows ${ }^{11}$ to suggest that this peculiar form of tumor represents a benign polyclonal proliferative disorder rather than a monoclonal malignant disease. Accordingly, some investigators have argued against cytotoxic chemotherapy for patients with Stage IV-S lesions, in favor of more conservative management. ${ }^{28}$ Our data do not support their position. Ancuploidy is universally accepted as a marker of malignant discase; morcover, in our four Stage D(IV-S) cases, there was a narrow dispersion of measurements of cellular DNA content around the modal values for $G_{0} / G_{1}$ hyperdiploid stem lines, demonstrating the monoclonal character of the abnormality of DNA content. ${ }^{1.14}$ Bccause of the difficulty of identifying Stage IV-S discase with certainty, the prolonged time required for it to resolve, and the possibility of progression to Stage IV, it seems prudent that each case of disseminated neuroblastoma be regarded as involving malignant, potentially fatal disease and be treated with five courses of cyclophosphamide and doxorubicin or another appropriate drug combination. ${ }^{29}$
The adverse prognostic information conveyed by diploid stem lines has definite therapeutic implications. In another study, ${ }^{18}$ sequentially scheduled cisplatin and teniposide proved highly active against disseminated neuroblastoma that was resistant to cyclophosphamide and doxorubicin, just as they did in the present study. Thus, it would seem reasonable to view diploid neuroblastoma as a special category of discase requiring alternative chemotherapy.

We are indeluted (o) Dr. Alvin M. Mauer for critical review of the manuscript; to L. Jan Graham, Shaton Noomer, L. Keith Brown, Barry Somerville, and Edward Wingfield for expert technical assistance; and to John Gilbert for editorial review. Patients with neuroblastoma and tumor samples were curolled in this study by all member institutions of the Pediatric: Oncology (iroup.

\section{REFERENCES}

1. Barlogie B, Drewinko B, Schumann J. et al. Cellular DNA content as a marker of neoplasia in man. Am J Med 1980; 69:195-203.

2. Barlogic B. Johnston DA. Smallwood L, et al. Prognostic implications of ploidy and proliferative activity in human solid tumors. Cancer Genet Cytogenet 1982; 6:17-28.

3. Barlogic B, Raber MN, Schumann J, et al. Flow cytometry in clinical cancer research. Cancer Res 1983; 43:3982-97.

4. Bunn PA Jr, Krasnow S, Makuch RW, Schlam ML, Schechter GP. Flow cytometric analysis of DNA content of bone marrow cells in patients with plasma cell myclona: clinical implications. Blood 1982; 59:528-35.

5. Green AA, Hayes FA, Hustu HO. Sequential cyclophosphamide and doxorubicin for induction of complete remission in children with disseminated neuroblastoma. Cancer 1981; 48:2310-7.

6. Finklestein JZ, Klemperer MR, Evans A, et al. Multiagent chemotherapy for children with metastatic ncuroblastoma: a report from Children's Cancer Study Group. Med Pediatr Oncol 1979; 6:179-88.

7. Evans AE, D'Angio GJ, Randolph J. A proposed staging for children with neuroblastoma: Children's Cancer Study Group A. Cancer 1971; 27.3748 .

8. D'Angio GJ, Evans AE, Koop CE. Special pattern of widespread neuroblastoma with a favourable prognosis. Lancet 1971; 1:1046-9.

9. Schwartz AD, Dadash-Zadeh M, Lec H, Swancy JJ. Spontaneous regression of disseminated neuroblastoma. J Pediatr 1974; 85:760-3.

10. Evans AE. Gerson J, Schnaufer L. Spontancous regression of neuroblastoma. Natl Cancer Inst Monogr 1976; 44:49-54.

11. Knudson AG Jr, Meadows AT. Regression of neuroblastoma IV-S: a genetic hypothesis. N Engl J Med 1980; 302:1254-6.

12. Wilson LMK, Draper GJ. Neuroblastoma, its natural history and prognosis: a study of 487 cases. Br Med J 1974; 3:301-7.

13. Krishan A. Rapid flow cytofluorometric analysis of mammalian cell cycle by propidium iodide staining. J Cell Biol 1975; 66:188-93.

14. Look AT, Melvin SL, Williams DL, et al. Ancuploidy and percentage of S-phase cells determined by flow cytometry correlate with cell phenotype in childhood acutc leukemia. Blood 1982; 60:959-67.

15. Ryan TA Jr, Joiner BL, Ryan BF. Minitab student handbook. North Scituatc, Mass.: Duxbury Press, 1979.

16. Pagano M, Halvorsen KT. An algorithm for finding the exact significance levels of $r x c$ contingency tables. J Am Stat Assoc 1981; 76:931-4.

17. Conover WJ. Practical nonparametric statistics. New York: John Wiley, 1971.

18. Hayes FA, Green AA, Casper J, Cornet J, Evans WE. Clinical evaluation of sequentially scheduled cisplatin and VM26 in neuroblastoma: response and toxicity. Cancer 1981; 48:1715-8.

19. Breslow N, McCann B. Statistical estimation of prognosis for children with neuroblastoma. Cancer Res 1971; 31:2098-103.

20. Hann H-WL, Evans AE, Cohen IJ, Leitmeyer JE. Biologic differences between neuroblastoma stages IV-S and IV: measurement of serum ferritin and E-roselte inhibition in 30 children. $N$ Engl J Med 1981: 305:4259.

21. Pinkel D. Differences between neuroblastoma stages IV-S and IV. N Engl J Med 1981: 305:1418-9.

22. 7eltzer PM, Marangos PJ, Parma AM, et al. Raised neuron-specific enolase in serum of children with metastatic neuroblastoma: a report from the chilUren's Cancer Study Group. Lancet 1983; 2:361-3.

23. Barlogie B, Hittelman W. Spitzer G, et al. Correlation of DNA distribution abnormalities with cytogenctic findings in human adult leukenia and lymphoma. Cancer Res 1977; 37:4400-7. 
24. Brodeur GM, Green AA, Hayes FA, Williams KJ, Williams DI., Tsiatis AA. Cytogenetic features of human ncuroblastomas and cell lines. Cancer Res 1981; 41:4678-86.

25. Williams DI, Tsiatis A. Brodeur GM, et al. Prognostic importance of chromosome number in 136 untreated children with acute lymphoblastic leukemia. Blood 1982; 60:864-71.

26. Secker-Walker LM, Swansbury GJ, Hardisty RM, et al. Cytogenetics of acute lymphoblastic leukaemia in children as a factor in the prediction of long-term survival. Br J Haematol 1982: 52:389-99.

27. Third International Workshop on Chromosomes in Leukemia, Lund, Sweden, July 21-25, 1980. Cancer Genet Cytogenet 1981; 4:96-137.

28. Evans AE. Baum E, Chard R. Do infants with Stage IV-S ncuroblastoma need treatment? Arch Dis Child 1981; 56:271-4.

29. Hayes FA, Green AA. Neuroblastoma. Pediatr Ann 1983; 12:366-73.

\section{MEDICAL PROGRESS}

\section{THE PRIMARY IMMUNODEFICIENCIES}

\section{(First of Two Parts)}

Fred S. Rosen, M.D., Max D. Cooper, M.D., and Ralph J. P. Wediwood, M.D.

\section{$\mathrm{T}$} THE analysis of immunodeficiency diseases depends heavily on an understanding of the normal development and function of cells belonging to the immune system. The two principal types of cells involved in immune responses are $T$ and $B$ cells. They are generated in different microenvironments, devclop as separate lineages, and express different kinds of antigen receptors, but they work together in discriminating between self and nonself.

$\mathrm{T}$ and $\mathrm{B}$ cells are not alone in manning host defense, however. By means of their soluble products, lymphokines and antibodies, they recruit macrophages, neutrophils, cosinophils, basophils, mast cells, and natural killer cells to participate in immune responses. Natural killer cells, the most recently recognized members of the immune system, have drawn special attention because they can spontaneously kill tumor and virus-infected cells and may also help to regulate immune responses.

$T$ cells take the lead in immune responses when they recognize foreign antigens presented on the surface of macrophages, dendritic cells, and Langerhans' cells in the skin. Activated in this manner, $T$ cells produce soluble factors that engage other $\mathrm{T}$ and $\mathrm{B}$ cells in the response. This network of cellular interactions, set of by helper $\mathrm{T}$ cells, is counterbalanced by the activation of suppressor $\mathrm{T}$ cells, which in turn dampen the immunc response. Even without $B$ cells and their antibody products, $\mathrm{T}$ cells can successfully orchestrate the control of viral and fungal infections, reject grafts of forcign tissues, and cause delayed hypersensitivity reactions. Collectively, these types of immune responses are termed "cellular immunity." On the other hand, with help from the $\mathrm{T}$ cell, the activated $\mathrm{B}$ cell divides and matures into plasma cells, which sccrete anti-

\footnotetext{
From the Departments of Pediatrics, Harvard Medical School, Boston, University of Alabama School of Medicine, Birmingham, Ala., and University of Washington School of Medicine. Scattle. Address reprint requests to Dr. Rosen at the Department of Pediatrics, Children's Hospital Medical Center, 300 Longwood Ave., Boston, MA 02115.
}

bodies. Examples of the ensuing humoral immunity include elimination of bacterial invaders, neutralization of toxins, prevention of viral reinfection, and immediate allergic reactions.

\section{T Cells}

Pluripotent stem cells of mesenchymal origin give rise to $\mathrm{T}$ cells, as well as to all the other types of blood cells (Fig. 1). ${ }^{2}$ Certain stem-cell progeny may become precommitted to development in the $T$ lineage even before migration to the thymus. An attractive alternative hypothesis is that pluripotent stem cells are induced to begin T-cell differentiation only after they enter the thymic microenvironment. Early in embryonic life the endodermal cells of the third and fourth pharyngeal pouches that are destined to form the thymus begin their migration to the precordial region in the thoracic mediastinum. ${ }^{3}$ (Neighboring epithelial cells give rise to the parathyroid glands and calcitoninproducing type $\mathrm{G}$ cells in the thyroid.) At a precise point in embryonic development the epithelial thymus begins to attract precursor stem cells from the circulation into its microenvironment. ${ }^{4}$ The first wave of stem-cell influx into the thymus occurs around the eighth weck of gestation, and the thymus quickly becomes filled with an expanding population of lymphoid-cell progeny. ${ }^{3}$ As an active lymphopoietic tissuc, the thymus grows to approximately $70 \mathrm{~g}$ in weight by the end of infancy. After populating the body with long-lived ' $T$ cells, thymopoictic activity gradually declines with age; the average size of the thymus is only around $3 \mathrm{~g}$ in elderly people.

Within the lobular units of the thymus, a gradient exists from cortex to medulla in the rate of thymocyte proliferation and the degree of maturation. ${ }^{5}$ Precursor stem cells landing in the outer cortex are induced to become thymocytes and to enter the cell cycle, dividing every 8 to 10 hours. This population explosion leads to crowding of the cortical areas with relatively immature thymocytes. As they move on to the medullary region, the thymocytes cease to divide and under- 